\title{
EVALUATION PROMPTING TRANSITION FROM ENHANCED TO ROUTINE SURVEILLANCE OF LYMPHOGRANULOMA VENEREUM (LGV) IN THE NETHERLANDS
}

\author{
Marten Kivi1,2, F. D.H. Koedijk (femke.koedijk@rivm.nl) ${ }^{1}$, M van der Sande ${ }^{1}$, M J W van de Laar ${ }^{1,3}$ \\ 1. Rijksinstituut voor Volksgezondheid en Milieu (RIVM, National Institute for Public Health and Environment), Centrum \\ Infectieziekte-bestrijding (CIb, Centre for Infectious Diseases Control), Bilthoven \\ 2. European Programme for Intervention Epidemiology Training (EPIET) \\ 3. European Centre for Disease Prevention and Control (ECDC), Stockholm, Sweden (present affiliation)
}

In 2004, a lymphogranuloma venereum (LGV) epidemic among men who have sex with men in the Netherlands motivated the introduction of enhanced surveillance. We evaluated the acceptability of the enhanced LGV surveillance in the Netherlands in 2004-2005 to provide recommendations for future surveillance. Completeness of requested patient information was analysed. All 12 sexually transmitted infection (STI) health services participating in the 2004-2005 STI surveillance completed evaluation questionnaires and rated surveillance system features from $1=$ "very poor" to $5=$ "very good". Information from enhanced LGV surveillance was available for 34 (33\%) of 104 cases. For these 34 cases, median proportions of response decreased successively for clinical information (100\%), sexual anamnesis (71\%) and details about the last sex partners (44\%). A median score of 4 ("good") was assigned to simplicity, required resources and surveillance information requested and distributed. Seven respondents favoured continuation of LGV surveillance, whereof six preferred modifications, usually meaning less extensive surveillance. In conclusion, the enhanced LGV surveillance was generally regarded as adequate. However, it was limited by low completeness, underlining the need to keep requested information to a minimum. The routine STI surveillance now includes LGV diagnosis and, following this evaluation, the additional enhanced surveillance was discontinued. However, occasional cases justify alertness and LGV remains under routine STI surveillance in the Netherlands.

\section{Introduction}

\section{Lymphogranuloma venereum (LGV) in Europe}

Since 2004, LGV has been recognised as a public health concern among men who have sex with men (MSM) in western Europe, particularly in the United Kingdom, France, Germany and the Netherlands [1-6]. Chlamydia trachomatis serovar (genotype) L1, L2 or L3, the LGV causative agent, is associated with more invasive disease than the urogenital serovars D-K [1]. LGV can present with a genital or rectal ulcer or papule, proctitis, mucoid or purulent anal discharge, rectal bleeding, anal spasms, tenesmus, constipation, inguinal lymphadenopathy (buboes), pain and general malaise. The initial alert regarding the present epidemic was based on the observation of a cluster of cases among a subgroup of MSM in Rotterdam [7-11]. Typically, the cases presented with proctitits, were HIV positive, had concomitant STIs and reported having had unprotected sex with many partners in the Netherlands and abroad.
To date, nearly 250 cases have been identified in the Netherlands, the majority belonging to the principal risk group $[3,12,13]$.

\section{Enhanced LGV surveillance in the Netherlands}

In the Netherlands, a national LGV work group was established in January 2004, a case definition was developed (Table 1), and voluntary enhanced LGV surveillance was launched in March 2004 [7-9]. The objectives of the LGV surveillance were to; 1) assess the magnitude of the outbreak, 2) describe epidemiological aspects and, 3) identify risk factors in order to target prevention activities. A prerequisite for successful LGV surveillance was national awareness with regard to the LGV surveillance, clinical manifestation and diagnosis among STI physicians, human immunodeficiency virus (HIV) treatment centres, gastroenterologists and other. Corresponding information was distributed through email updates, national and international alerts [7-10] and information at the RIVM website.

The enhanced LGV surveillance was integrated with the routine internet-based STI surveillance (SOAP) and applied the case definition in Table 1. In 2004-2005, SOAP was based on 12 STI clinics and municipal health services that reported STI cases to the National Institute for Public Health and the Environment (RIVM) (Figure). As well as LGV being included in SOAP, other health professionals were also invited to report LGV cases in SOAP or on paper to the local municipal health service or the RIVM. The municipal health services and the RIVM exchanged information regarding LGV cases. In addition to the primarily clinical information about other STIs routinely collected in SOAP, the enhanced LGV surveillance requested more detailed information through an LGV-specific patient form. The additional information included LGV clinical manifestation, diagnostics, treatment and detailed information about sexual behaviours and meeting places, primarily during the past six months. RIVM summarised data and distributed feedback information to local and national stakeholders in the form of annual reports, presentations and email updates.

LGV cases have also been identified after the initial cluster, demonstrating that LGV is likely to remain on the public health agenda $[12,13]$. In this context, we evaluated the acceptability of the enhanced LGV surveillance in the Netherlands in 2004-2005 to provide recommendations for future surveillance. 


\section{Methods}

Acceptability of the enhanced LGV surveillance in the Netherlands in 2004-2005 was estimated by completeness of requested information and rating of surveillance system features. Epidemiological analyses of the information collected in the enhanced surveillance have been published elsewhere [3].

\section{Completeness}

First, completeness of the requested LGV patient information was measured by the proportion of reported patients for whom requested forms had been obtained. Second, for different sections of the LGV patient form, the median proportion of response and the interquartile range (IQR) were calculated (Table 2). Furthermore, timeliness was measured by the duration between symptom onset, patient consultation and creation of a report in SOAP.

\section{F I G U R E}

The enhanced lymphogranuloma venereum (LGV) surveillance system integrated with SOAP ${ }^{\star}$ in the Netherlands in 2004-2005

Local level

National level

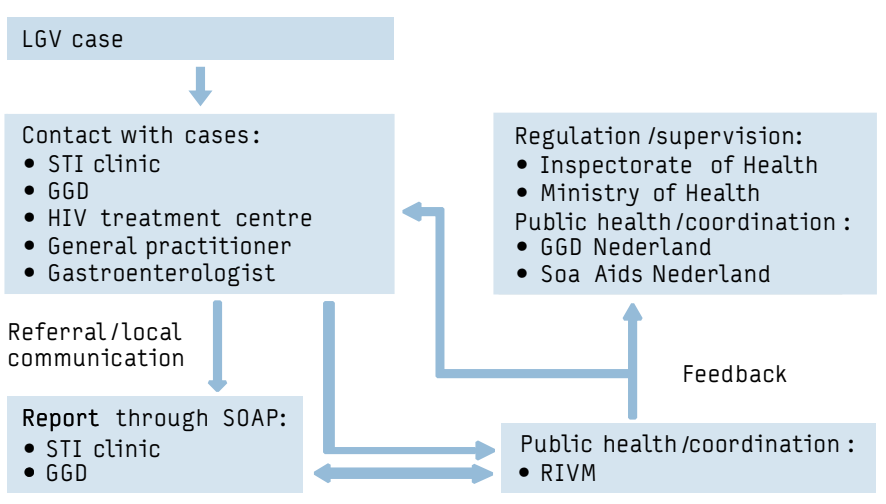

Report in enhanced LGV surveillance

*SOAP: surveillance system for sexually transmitted infections

Note: Human immunodeficiency virus (HIV); lymphogranuloma venereum (LGV); municipal health service (GGD);

National Institute for Public Health and the Environment (RIVM); sexually transmitted infection (STI); GGD Nederland is a national association for GGDs; Soa Aids Nederland is a national expert centre for STI and HIV.

T A B L E

Lymphogranuloma venereum (LGV) surveillance case definition in the Netherlands in 2004-2005

\begin{tabular}{|c|c|c|}
\hline \multicolumn{3}{|c|}{ LGV surveillance case definition* } \\
\hline Confirmed case & Probable case & Possible case \\
\hline $\begin{array}{l}\text { Anorectal syndrome OR } \\
\text { contact of confirmed } \\
\text { case AND positive } \\
\text { C. trachomatis PCR } \\
\text { (urine/rectum) AND } \\
\text { positive or unknown C. } \\
\text { trachomatis serology } \\
\text { AND C. trachomatis } \\
\text { serovar L1-L3 }\end{array}$ & $\begin{array}{l}\text { Anorectal syndrome OR } \\
\text { contact of confirmed } \\
\text { case AND positive } \\
\text { C. trachomatis } \\
\text { serology AND positive } \\
\text { C. trachomatis PCR } \\
\text { (urine/rectum) }\end{array}$ & $\begin{array}{l}\text { Anorectal syndrome } O R \\
\text { contact of confirmed } \\
\text { case AND positive } C \text {. } \\
\text { trachomatis serology }\end{array}$ \\
\hline
\end{tabular}

* As outlined in the user guidelines of the enhanced LGV surveillance

\section{Rating of surveillance system features and usefulness}

In May-August 2006, all 12 STI health services that participated in the 2004-2005 routine STI surveillance completed evaluation questionnaires. SOAP in general and the enhanced LGV surveillance in SOAP were ranked in terms of simplicity, collected information, feedback information, required resources and training of staff

\section{T A B L E}

Median proportions of response in patient forms received for 34 (33\%) of 104 cases as part of the enhanced lymphogranuloma venereum (LGV) surveillance in the Netherlands in 2004-2005

\begin{tabular}{|c|c|}
\hline Section of patient form & $\begin{array}{l}\text { Median proportion of } \\
\text { response in percent } \\
\text { (interquartile range) }\end{array}$ \\
\hline \multicolumn{2}{|l|}{ Clinical information } \\
\hline Section overall & $100(88-100)$ \\
\hline Clinical manifestation and anamnesis & $100(70-100)$ \\
\hline Diagnostics, treatment and care & $100(83-100)$ \\
\hline \multicolumn{2}{|l|}{ Sexual anamnesis } \\
\hline Section overall & $71(50-78)$ \\
\hline Basic anamnesis & $76(61-83)$ \\
\hline Techniques and meeting places & $65(46-74)$ \\
\hline \multicolumn{2}{|l|}{ Details about five last sex partners } \\
\hline Section overall & $44(32-59)$ \\
\hline Partner 1 & $74(69-74)$ \\
\hline Partner 2 & $59(56-59)$ \\
\hline Partner 3 & $44(44-44)$ \\
\hline Partner 4 & $32(32-32)$ \\
\hline Partner 5 & $32(32-32)$ \\
\hline
\end{tabular}

\section{TA B L E 3}

Ratings of the sexually transmitted infection (STI) surveillance system SOAP, the enhanced lymphogranuloma venereum (LGV) surveillance and LGV information and knowledge, as reported by the 12 STI health services that participated in the STI surveillance in the Netherlands in 2004-2005

\begin{tabular}{|c|c|c|}
\hline Group of items & $\begin{array}{c}\text { Number of scores } \\
\text { available } / \text { requested } \\
\text { (percent) }\end{array}$ & $\begin{array}{c}\text { Median score } \\
\text { (interquartile } \\
\text { range)** }\end{array}$ \\
\hline SOAP in general ${ }^{\star \star \star}$ & $36 / 60(60)$ & $4(4-4)$ \\
\hline LGV in SOAP ${ }^{\star \star \star}$ & $24 / 60(40)$ & $4(3-4)$ \\
\hline $\begin{array}{l}\text { Distributed information, } \\
\text { March-April } 2004^{\star \star \star \star}\end{array}$ & $49 / 60(82)$ & $4(4-4)$ \\
\hline $\begin{array}{l}\text { Distributed information, } \\
\text { May 2004-December } 2005^{\star \star \star \star}\end{array}$ & $49 / 60(82)$ & $4(4-4)$ \\
\hline $\begin{array}{r}\text { In-house LGV knowledge, } \\
\text { April } 2004^{\star \star \star \star * \star}\end{array}$ & $50 / 72(69)$ & $4(4-4)$ \\
\hline $\begin{array}{l}\text { In-house LGV knowledge, } \\
\text { at present }\end{array}$ & $58 / 72(81)$ & $4(3-4)$ \\
\hline
\end{tabular}

Unavailable scores consisted of the answer alternative "don't know” or missing data.

** 5="very good", 4="good", 3="mediocre", 2="poor" and 1="very poor"

*** Included features: simplicity, collected information, feedback, required resources, required training

$\star \star \star \star$ Included features: general impression, usefulness, simplicity, timeliness, Included feature

$\star \star \star \star \star$ Included features: clinical manifestation, risk groups in the Netherlands, epidemic in the Netherlands, diagnostics, aim of surveillance, LGV in SOAP 
Distributed information about the enhanced LGV surveillance, including instructions and feedback, was ranked as for genera impression, usefulness, simplicity, timeliness and completeness. Further, in-house LGV knowledge was ranked with regard to LGV clinical manifestation, risk groups, epidemic, diagnostic methods, surveillance objective and surveillance in SOAP. The answer alternatives composed a score; 5="very good", 4="good", 3="mediocre", 2="poor" and 1="very poor". The median score and IQR were calculated for each item and group of items (Table 3 ).

The questionnaire also enquired about perceived usefulness of information collected in the enhanced LGV surveillance and the prospects for future LGV surveillance. To gather further comments on the questionnaire items, we interviewed four STI health services who had diagnosed the majority (79\%) of LGV cases in 2004-2005.

\section{Results}

\section{Completeness}

Of 114 LGV cases in the Netherlands in 2004-2005, 10 (9\%) were retrospectively reported and could not be contacted for inclusion in the enhanced LGV surveillance [3]. Of the remaining 104 reported cases, 34 (33\%) were reported in the enhanced surveillance with accompanying LGV patient forms. Of these, 31 (91\%) were reported to the RIVM through SOAP while three were reported on paper and entered in SOAP at the RIVM. A large number of missing forms was attributed to one large STI clinic that at that time did not use SOAP to report STI cases. However, this STI clinic provided basic information on LGV cases, including consult date, basic demographics, sexual preference, other STI diagnoses and LGV clinical presentation (inguinal or anorectal). Information on detailed symptoms, date of onset, treatment and sexual anamnesis was not available for these cases.

For the 34 received patient forms, the response decreased as the questions became increasingly detailed (Table 2). Median proportions of response for different sections decreased from $100 \%$ for clinical symptoms, diagnostics and treatment to $71 \%$ for sexual anamnesis and to $44 \%$ for details about the five last sex partners. For the latter section, median proportions of response also decreased successively for details of the first to the fifth partner (74\%, 59\%, 44\%, 32\%, and 32\%). The date of symptom onset was known for seven, estimated for 24 and unknown for three patients. The median duration from onset to consultation was 57 days (IQR 29-96 days). The median duration between patient consultation and creation of a report in SOAP was 20 days (IQR 0-62 days), which is a usual time period for obtaining laboratory results [14].

\section{Rating of surveillance system features}

The 12 STI health services provided 266 (69\%) of 384 requested scores, while the remainder consisted of either the answer alternative "don't know" or missing data (Table 3). Overall, the ratings of different features of the enhanced LGV surveillance corresponded to a median score of 4 ("good") (IQR 4-4). The items relating to SOAP in general and the LGV surveillance in SOAP generated median scores of 4 (IQR 4-4 and 3-4, respectively). The information distributed about the LGV surveillance in the start-up phase (March-April 2004) and thereafter (May 2004-December 2005) also yielded median scores of 4 (IQR 4-4 and 4-4). The STI health services' initial (April 2004) and present in-house LGV knowledge corresponded to median scores of 4 (IQR 4-4 and 3-4, respectively). The above picture was supported by the interviews.
Seven respondents had experience of LGV patients, but results did not appear to differ between respondents with and without LGV experience.

\section{Future LGV surveillance}

Of the 12 STI health services, eight regarded the information collected by the enhanced surveillance in 2004-2005 as useful, while one regarded it too detailed and three did not provide an opinion. Six respondents favoured continued LGV surveillance but in modified form, one respondent preferred continued LGV surveillance in its present form, two deemed that there should be no LGV surveillance at all, while three did not provide a preference with regard to future LGV surveillance. Modifications of the enhanced LGV surveillance usually referred to collection of less information as clarified in comment fields and interviews. Downscaling of the enhanced surveillance was motivated by perceptions of limited public health importance and low usefulness outside outbreak situations.

\section{Discussion}

The present evaluation of the enhanced LGV surveillance in the Netherlands in 2004-2005 showed that participating STI health services generally regarded the surveillance as adequate. This notion is limited by the occasionally low proportions of response in the evaluation questionnaire (Table 3). This applies in particular to the enhanced LGV surveillance section, probably because not all respondents had direct experience of LGV cases and thus of the enhanced surveillance. The tendency towards satisfied ratings contrasts with the low completeness of requested information, especially the low proportion of received patient forms (33\%), which indicates that the enhanced LGV surveillance did not fully function as intended.

\section{Usefulness of the enhanced LGV surveillance}

The patient information received through the enhanced LGV surveillance confirmed the initial observation of an epidemic among a high-risk subgroup of MSM [3]. The basic information available for reported cases without the patient form showed a similar picture. This absence of evidence of spill-over into other population groups is important when devising public health responses. In the context of the first surveillance objective, this evaluation offers no reason to suspect that there were considerable numbers of not notified diagnosed LGV cases, although underdiagnosis cannot be excluded. With regard to the other two surveillance objectives, the cases have been described elsewhere [3]. Thus, it can be concluded that the enhanced LGV surveillance provided information according to the stated objectives.

However, the usefulness of the collected patient information was limited by low completeness, notably the low proportion of available patient forms (33\%). Moreover, low proportions of response could be associated with detailed questions regarding sexual anamnesis. This may be attributed to the intimate nature of the questions, the time required to complete the patient form and a limited perceived usefulness of the most detailed questions. Low response for detailed behavioural questions has been noted in the corresponding enhanced LGV surveillance in the United Kingdom [4] and France (Anne Gallay, personal communication, 26 March 2007), and the Dutch form stood out in that it asked for more detailed information about the five last sex partners. This evaluation highlights that a prerequisite for efficient surveillance is to keep requested information to the minimum required for public health action. 


\section{Future LGV surveillance}

In 2006-2007, an increase in LGV cases in Amsterdam confirmed a need for sustained alertness and surveillance [12, 13]. Since 2004, the routine STI surveillance in SOAP has been gradually expanded and now includes LGV diagnosis and serovar. Furthermore, information is presently routinely collected on basic demographics, sexual preference, number of sex partners during the past six months, other STIs, condom use during the last sexual contact and unprotected contacts abroad during the past three months. Thus, the routine STI surveillance alone should presently, in conjunction with alertness among clinicians, provide a sufficient basis for public health action. If deemed necessary, such action may include research on clinical and behavioural characteristics of cases in order to follow the epidemic's development in more detail.

The present evaluation was presented at a national STI expert meeting and a proposal to discontinue the enhanced LGV surveillance was accepted. The revised objective for future LGV surveillance is to monitor and analyse trends in LGV cases in the Netherlands and thus obtain basic information to guide public health action. Furthermore, the Dutch case definition may be adapted according to the standard case definition of the European Centre for Disease Prevention and Control (ECDC), which could reduce differences among European countries [2-5].

\section{Conclusion}

The enhanced LGV surveillance was useful to confirm risk groups [3] and the present evaluation indicates that the surveillance was generally regarded as adequate. Public health usefulness was limited by low completeness of information requested through the LGV patient form. The low completeness may be attributed to occasionally low acceptability and too detailed questions, underlining the need to keep requested information to a minimum. The routine STI surveillance has been expanded and now includes LGV diagnosis, reducing the added value of the enhanced LGV surveillance. Accordingly, in July 2007, following this evaluation, the enhanced LGV surveillance was discontinued. However, occasional cases justify alertness and LGV remains integrated in the routine STI surveillance in the Netherlands.

\section{Acknowledgments}

We thank the participating STI health services and the LGV work group. venereum epidemic among men who have sex with men. Euro Surveill. 2005;10(6):E050602.1. Available from: http://www.eurosurveillance.org/ ew/2005/050602.asp\#1

7. Götz HM, Ossewaarde JM, Nieuwenhuis RF, van der Meijden WI, Dees J, Thio B, et al. Cluster van lymphogranuloma venereum onder homoseksuele mannen in Rotterdam, met grensoverschrijdende gevolgen. Ned Tijdschr Geneeskd. 2004;148(9):441-2.

8. Cluster van lymphogranuloma venereum onder homoseksuele mannen in Rotterdam: grensoverschrijdende gevolgen. Infectieziektenbulletin. 2004;15(2):41-2.

9. Götz H, Nieuwenhuis $R$, Ossewaarde T, Thio B, van der Meijden W, Dees J, et al. Preliminary report of an outbreak of lymphogranuloma venereum in homosexual men in the Netherlands, with implications for other countries in western Europe. Euro Surveill. 2004;8(4):E040122. Available from: http:// www.eurosurveillance.org/ew/2004/040122.asp\#1

10. Van de Laar MJW, Götz HM, de Zwart 0, van der Meijden W, Ossewaarde JM, Thio $\mathrm{HB}$, et al. Lymphogranuloma venereum among men who have sex with men Netherlands, 2003-2004. MMWR Morb Mortal Wkly Rep. 2004;53(42):985-8.

11. Nieuwenhuis RF, Ossewaarde JM, Götz HM, Dees J, Thio HB, Thomeer MG, et al. Resurgence of lymphogranuloma venereum in Western Europe: an outbreak of Chlamydia trachomatis serovar 12 proctitis in the Netherlands among men who have sex with men. Clin Infect Dis. 2004;39(7):996-1003.

12. Koedijk FD, de Boer IM, de Vries HJC, Thiesbrummel HFJ, van der Sande MAB. An ongoing outbreak of lymphogranuloma venereum in the Netherlands, 2006-2007. Euro Surveill. 2007;12(4):E070419.2. Available from: http://www. eurosurveillance.org/ew/2007/070419.asp\#2

13. Koedijk FDH, de Boer IM, de Vries HJC, Thiesbrummel HFJ, van Leeuwen AP, van der Sande MAB. Aanhoudende LGV-uitbraak in Nederland. Infectieziektenbulletin. 2007;18(5):159-61.

14. Van de Laar MJW. Gebruik van SOAP in de SOA-surveillance. Infectieziektenbulletin.

This article was published on 3 April 2008

Citation style for this article: Kivi M, Koedijk FD, van der Sande M, van de Laar MJ. Evaluation prompting transition from enhanced to routine surveillance of E Available online: http://www.eurosurveillance.org/ViewArticle.aspx?ArticleId $=8087$

\section{References}

1. Van de Laar MJ. The emergence of LGV in Western Europe: what do we know, what can we do? Euro Surveill 2006:11(9):146-8. Available from: http://www. eurosurveillance.org/em/v11n09/1109-221.asp

2. Herida M, de Barbeyrac B, Sednaoui P, Scieux C, Lemarchand N, Kreplak G, et al. Rectal lymphogranuloma venereum surveillance in France 2004-2005. Euro Surveill. 2006;11(9):155-6. Available from: http://www.eurosurveillance.org/ em/v11n09/1109-224.asp

3. Van de Laar MJ, Koedijk FD, Gotz HM, de Vries HJ. A slow epidemic of LGV in the Netherlands in 2004 and 2005. Euro Surveill. 2006;11(9):150-2. Available from: http://www.eurosurveillance.org/em/v11n09/1109-222.asp

4. Ward H, Martin I, Macdonald N, Alexander S, Simms I, Fenton K, et al. Lymphogranuloma venereum in the United kingdom. Clin Infect Dis. 2007;44(1):26-32.

5. Bremer V, Meyer T, Marcus U, Hamouda O. Lymphogranuloma venereum emerging in men who have sex with men in Germany. Euro Surveill. 2006;11(9):152-4. Available from: http://www.eurosurveillance.org/em/v11n09/1109-223.asp

6. Van de Laar MJ, Fenton KA, Ison C. Update on the European lymphogranuloma 